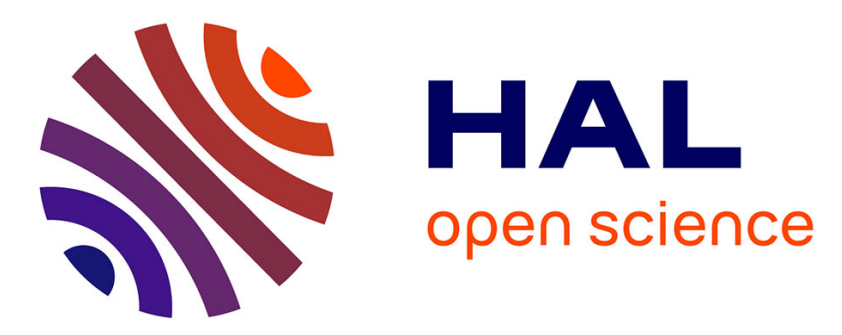

\title{
Genotypic Influence on Metal Ion Mobilization and Sequestration via Metal Ion Ligand Production by Wheat
}

\author{
Teresa W-M Fan, Fabienne Baraud, Richard M Higashi
}

\section{- To cite this version:}

Teresa W-M Fan, Fabienne Baraud, Richard M Higashi. Genotypic Influence on Metal Ion Mobilization and Sequestration via Metal Ion Ligand Production by Wheat. Nuclear Site Remediation, 2001, 10.1021/bk-2001-0778.ch025 . hal-02588086

\section{HAL Id: hal-02588086}

\section{https://hal-normandie-univ.archives-ouvertes.fr/hal-02588086}

Submitted on 15 May 2020

HAL is a multi-disciplinary open access archive for the deposit and dissemination of scientific research documents, whether they are published or not. The documents may come from teaching and research institutions in France or abroad, or from public or private research centers.
L'archive ouverte pluridisciplinaire HAL, est destinée au dépôt et à la diffusion de documents scientifiques de niveau recherche, publiés ou non, émanant des établissements d'enseignement et de recherche français ou étrangers, des laboratoires publics ou privés. 
RESERVE THIS SPACE

\title{
Genotypic Influence on Metal Ion Mobilization and Sequestration via Metal Ion Ligand Production by Wheat
}

\author{
Teresa W.-M. Fan ${ }^{1}$, Fabienne Baraud ${ }^{1}$, and Richard M. Higashi ${ }^{2}$ \\ ${ }^{1}$ Department of Land, Air and Water Resources, and ${ }^{2}$ Crocker Nuclear \\ Laboratory, University of California, One Shields Ave., Davis, CA 95616- \\ 8627, U.S.A.
}

Intracellular production and root exudation of metal ion ligands (MIL) are keys to metal ion mobilization and sequestration by vascular plants. This is well-exemplified by the exudation of phytosiderophores such as mugineic acid and derivatives in the acquisition of $\mathrm{Fe}$ (III) and $\mathrm{Zn}$ (II) by graminaceous plants. However, the genetic and biochemical mechanism(s) for the mobilization and sequestration of most pollutant metal ions remain unknown, due largely to a lack of knowledge in MIL involved in the process. This information is critically needed for developing and engineering plant-based remediation of metal contamination at DOE, DOD, and other industrial facilities. Here, we investigated the influence of elevated metal ( $\mathrm{Zn}, \mathrm{Cu}, \mathrm{Ni}, \mathrm{Mn}$, and $\mathrm{Cd})$ ion treatment on root

\section{RESERVE THIS SPACE}


exudation, tissue MIL profiles, and metal accumulation in Chinese spring (CS) wheat, its 7 genotypes prepared from disomic addition of the wheatgrass chromosomes to CS, and the amphiploid between the two species. Broad-screen and structure elucidating nuclear magnetic resonance spectroscopy and gas chromatography-mass spectrometry were employed to obtain comprehensive profiles of MIL in root exudates and tissues, difficult to achieve with conventional approaches. In addition, thiol-rich peptide profiles were acquired using fluorescent bromobimane tagging and sodium dodecyl sulfatepolyacrylamide gel electrophoresis, while comprehensive metal ion profiles were obtained using X-ray fluorescence. Genotypic covariation was noted between metal ions ( $\mathrm{Mn}, \mathrm{Fe}$, $\mathrm{Cu}$, and $\mathrm{Zn}$ ) and such MIL as 2'-deoxymugineic acid and acetate in root exudates and citrate and malate in roots. Profiles of phytochelatin-like peptides also displayed genotypic variations and strong correlation with $\mathrm{Cd}$ accumulation. These results suggest possible chromosomal location(s) of gene(s) governing metal ion mobilization and sequestration in wheat.

\section{Introduction}

Vascular plants are known to utilize two different strategies to mobilize Fe(III) from soils 1. The so-called Strategy II plants (graminaceous monocots) release powerful iron chelators into root exudates to complex Fe(III) for uptake. These chelators, which are termed phytosiderophores (PS) when applied strictly to Fe acquistion, consist

principally of mugineic acid and its derivatives, 2'-deoxymugineic acid (2'-DMA) and 3-epi-hydroxymugineic acid (3-epi-DMA) ${ }^{2}$. In addition to $\mathrm{Fe}(\mathrm{III})$, PS also complex with other micronutrients such as $\mathrm{Zn}(\mathrm{II})$ and $\mathrm{Cu}(\mathrm{II})$ to facilitate their uptake by plants 3,4 . However, it is unclear 
whether PS are involved in the mobilization and uptake of pollutant metal ions (e.g. $\mathrm{Cd}(\mathrm{II}), \mathrm{Pb}$ (II), $\mathrm{Sr}(\mathrm{II}), \mathrm{Cs}(\mathrm{II})$ ) commonly found in contaminated soils including those at DOE facilities. Also uncertain is the involvement of exudate components other than PS in metal ion mobilization, for lack of a comprehensive knowldege of root exudate composition. Moreover, once absorbed, it is largely unknown how these pollutant ions (usually toxic to plants) are translocated to shoots or sequestered inside root cells. Insights into these questions are crucial to the design and implementation of plantbased remediation of metal contamination from soils and sediments.

Without prior knowledge of chemical composition, analysis of crude mixtures such as plant root exudates requires a profiling approach, for which we developed a combined nuclear magnetic resonance (NMR) spectroscopy and gas chromatography-mass spectrometry (GC-MS) method ${ }^{5}$. We have used this approach for simultaneous determination of known, unexpected, and even unknown metal ion ligands (MIL), in addition to PS, directly from crude exudates ${ }^{5}$. With this tool in hand, it is now possible to examine environmental and genetic factors influencing intracellular MIL and root exudation profiles, and their role in metal ion acquisition. Among known PS-releasing plants, wheat ranks as one of the highest in terms of PS production ${ }^{6}$. The principal PS released by common wheat is 2'-DMA which has a very high stability constant $\left(\mathrm{K}_{\mathrm{d}} \approx\right.$ $10^{33}$ ) towards $\mathrm{Fe}(\mathrm{III}){ }^{6,7}$. It seems reasonable to expect that some of the wheat relatives, in particular those inhabiting Fe-deficient environments, may have evolved even higher PS production. In the present study, we exploited the wealth of genetic stocks that have been developed for 
Lophopyrum elongatum (Host) Love, a diploid wheatgrass closely related to wheat, for study of the production of 2'-DMA and possibly other MIL, and in turn the consequences of such production on metal ion uptake. With these genetic stocks, we examined the influence of each chromosome of this species on root exudation, metabolite profiles, and metal accumulation under normal and elevated metal treatments. Covariation of 2'-DMA, thiol-rich peptides, and other MIL with acccumulation of $\mathrm{Mn}, \mathrm{Fe}, \mathrm{Cu}, \mathrm{Zn}$, and $\mathrm{Cd}$ by these genetic stocks made it possible to acquire insights into relationships between these compounds and the uptake and sequestration of specific heavy metals and potential chromosomal location of genes regulating these processes.

\section{Materials and Methods}

Plant growth. An octaploid amphiploid with three genome pairs of the hexaploid Triticum aestivum L. cv. Chinese Spring $(2 n=42$, genomes AABBDD) and one pair of genomes of dipoid wheatgrass, Lophopyrum elongatum (Host) Love $(2 n=14$, genomes EE) was produced by Rommel and Jenkins (1959) ${ }^{8}$ and supplied by J. Dvorak, Department of Agronomy, University of California, Davis. In addition to the amphiploid and Chinese Spring, a complete set of disomic addition lines of the $L$. elongatum chromosomes in Chinese Spring were investigated. The lines were produced by backcrossing the amphiploid to Chinese Spring and ultimately selecting plants with each of the seven chromosome pairs of $L$. elongatum added to the chromosome complement of Chinese Spring 9-11. 
These genetic stocks were designated here as follows: CS, the parental bread wheat; AgCS, the amphiploid; DA1E, DA2E, DA3E, DA4E, DA5E, DA6E, and DA7E, disomic addition lines with added chromosomes 1E, $2 \mathrm{E}, 3 \mathrm{E}, 4 \mathrm{E}, 5 \mathrm{E}, 6 \mathrm{E}$, and $7 \mathrm{E}$, respectively.

Seeds of the 8 genotypes plus CS were sterilized in 1:10 diluted commercial bleach, germinated in $0.5 \mathrm{mM} \mathrm{CaSO}_{4}$ on sterile germination paper at room temperature for 3-4 days, transplanted to six 10-L black polyethylene containers with 3 genotypes per container, and grown in onehalf strength Hoagland solution as modified from Epstein (1972) 12. The seedlings were aerated and maintained in a growth chamber (Sanyo) with a cycle of $16 / 8 \mathrm{~h} \mathrm{light/dark}$ periods, day/night temperature of $25 / 19^{\circ} \mathrm{C}$, and humidity regulated at $70 \%$. The $\mathrm{pH}$ of the nutrient solution was adjusted to 6 daily.

On day 10, metal treatment was initiated on one set of 9 genotypes (in 3 containers) by changing the nutriet solution to one-half strength Hoagland solution plus elevated levels of (in $\mathrm{mg} / \mathrm{L}$ ) of $\mathrm{Mn}(0.275), \mathrm{Ni}$ (0.15), $\mathrm{Cu}$ (0.08), $\mathrm{Zn}$ (0.33) plus $\mathrm{Cd}$ (at $1 \mathrm{mg} / \mathrm{L}$ as $\mathrm{CdSO}_{4}$ ) while the $\mathrm{Fe}$ concentration remained unchanged. The other set was unchanged and used as control. On day 20, the plants were harvested, separated into roots and shoots, lyophilized, and dry weight determined. The lyophilized tissues were pulverized into $<3 \mu \mathrm{m}$ particles and stored at $-70^{\circ} \mathrm{C}$ before analysis.

Root exudate collection. Three days before harvest, root exudates were collected 3 times each starting $2 \mathrm{~h}$ after the onset of the photoperiod, 
as previously described ${ }^{5}$. The three collections were combined, lyophilized, and dry weight determined.

Tissue metal contents. Total shoot and root metal contents were determined by energy dispersive X-ray fluorescence spectroscopy (EDXRF, JVAR Inc. EX3600 spectrometer). Tomato leaf tissues, including \#1573a from the National Institute of Standards and Technology, spiked with appropriate concentrations of relevant elements were used as calibration standards. The element concentrations of selected wheat tissues were also analyzed by ICP-AES after $\mathrm{HClO}_{4} / \mathrm{HNO}_{3}(1: 5)$ digestion to confirm the XRF analyses.

SH-rich proteins and peptides. Sulfhydryl $(\mathrm{SH})$-rich proteins and peptides from wheat tissues were extracted and derivatized simultaneously using a method modified from Fahey and Newton, $1987^{13}$, and subjected to SDS-PAGE (polyacrylamide gel electrophoresis) (modified from ${ }^{14}$ ). After PAGE, the gel was immediately fixed in $40 \%$ methanol plus $10 \%$ acetic acid and fluorescence-imaged using 365nm-excitation. Loss of peptides of $\leq 1 \mathrm{kDa}$ would occur with longer soaking in the fixing solution. After fluorescence imaging, the gel was stained in Coomassie blue G-250 (BioRad protocol) for comparison with the fluorescence pattern.

${ }^{1} H$ NMR and GC-MS of root metabolites and exudates. Root metabolites were extracted from pulverized root tissues and analyzed by GC-MS as described previously 5, 15, 16. The lyophilized exudates were redissolved in $1 \mathrm{~mL}$ of DDI water and subjected to both GC-MS and ${ }^{1} \mathrm{H}$ NMR analysis as previously described ${ }^{5}$, except that the ${ }^{1} \mathrm{H}$ NMR was performed at 11.75 Tesla on a Varian Unity Plus spectrometer housed in 
the DOE Environmental Molecular Science Laboratory (EMSL), Richland, WA. Peak assignments were based on previously assigned standards 5, 17. Acetate, 2'-DMA, glycinebetaine (GB), and an unknown compound in root exudates were quantified from the 1-D ${ }^{1} \mathrm{H}$ NMR spectra (cf. Figure 2) based on the intensity of peaks at 1.91, 4.09, 3.26, and 3.35 ppm, respectively, against that of the $\mathrm{CH}_{3}$ resonance at $1.47 \mathrm{ppm}$ of an external Ala standard 5,18. The quantification for the unknown was only tentative and the number of protons represented by the peak at $3.35 \mathrm{ppm}$ was assumed to be 2 based on the methylene assignment for this peak.

\section{Results and Discussion}

Biomass production. Under control conditions, the parent CS had the highest root and shoot biomass while DA2E, DA3E, and AgCS were among the lowest (data not shown). Under elevated metal treatment, the dry weight of both shoots and roots decreased for all wheat genotypes relative to the respective control, with the reduction ranging from 23 to $67 \%$ (data not shown). The biomass of DA3E, DA4E, DA6E, and DA7E was less impacted than that of $\mathrm{AgCS}$ and DA2E. Biomass reduction of a similar extent was observed with $\mathrm{Cd}$ treatment alone (Fan and Higashi, unpublished), so the reduction observed here was presumably due to $\mathrm{Cd}$ toxicity while other metal ions (i.e. $\mathrm{Mn}, \mathrm{Cu}, \mathrm{Ni}$, and $\mathrm{Zn}$ ) may have had only minor effects.

Compared to the CS parent, DA4E, DA6E, and DA7E also exhibited less metal-induced reduction in both root and shoot biomass, suggesting 
that addition of these L. elongatum chromosomes to CS confers some degree of tolerance to the metal treatment. The $\%$ change in the shoot/root dry weight ratio between treated and control plants differed among genotypes. DA1E to DA6E showed a negative change while DA7E, AgCS, and CS exhibited a positive change (data not shown), suggesting that genetic influence on shoot/root ratio may be altered by chromosomal additions of $1 \mathrm{E}$ to $6 \mathrm{E}$.

Tissue metal profiles. A notable genotypic variation in the $\mathrm{Mn}, \mathrm{Fe}$, and $\mathrm{Cu}$ content in both control and metal-treated roots was observed, with variation for $\mathrm{Zn}$ and Ni less pronounced (Figure 1A). In addition, metal treatment elicited a large increase in the concentrations of $\mathrm{Zn}, \mathrm{Fe}, \mathrm{Cu}$, and $\mathrm{Ni}$ but a slight reduction for Mn content in roots of all lines, with $\mathrm{Zn}$ showing the highest increase (up to 10 fold) (Figure 1A). This level of $\mathrm{Zn}$ accumulation was disproportionately greater than the $\mathrm{Zn}$ elevation in the treatment, which could be related to the co-treatment with $\mathrm{Cd}$. $\mathrm{Cd}$ treatment alone caused a $>2$-fold increase in $\mathrm{Zn}$ uptake into wheat roots under control conditions (Fan and Higashi, unpublished data). Since Zn and $\mathrm{Cd}$ are both Group IIB elements, it is possible that they share a similar uptake mechanism.

At $1 \mathrm{mg} / \mathrm{L}$, Cd treatment led to 80-200 fold accumulation of $\mathrm{Cd}$ in the roots of the 9 lines, with $\mathrm{AgCS}$ and DA3E showing the highest extent of accumulation (Figure 1A). This level of accumulation argues for a selective uptake mechanism for $\mathrm{Cd}$, while the lack of enhanced $\mathrm{Mn}$ accumulation suggests feedback control for Mn uptake. Although

Figure 1. Genotypic variations in wheat tissue metal content under control and elevat, treatments. Metal contents of roots (A) and shoots (B) were acquired using ED-XRF as des, Materials and Methods. Each graph represents results for an element. The gray bar (left) ( and black circle (right ordinate) respectively denote control and metal-treated tissues, abscissa for each graph are the nine genotypes $1 E, 2 E, 3 E, 4 E, 5 E, 6 E, 7 E, A g C S$, and CS. 
DA2E, DA3E, and the amphiploid had regularly higher root concentrations of $\mathrm{Mn}, \mathrm{Fe}$, and $\mathrm{Zn}$, these genotypes also had the lowest biomass production, which may be a consequence of accumulating "toxic" levels of these metal ions. More importantly, the result suggests that the gene(s) governing the uptake of these metal ions may reside on $L$. elongatum chromosomes $2 \mathrm{E}$ and $3 \mathrm{E}$.

In contrast to roots, $\mathrm{Mn}$, instead of $\mathrm{Fe}$, was the most concentrated metal ion in shoots of all genotypes under control growth (Figure 1B). This suggests a higher translocability of Mn in wheat. Shoots of all genotypes also exhibited variations in their metal content, but to a lesser extent than roots, except for $\mathrm{Ni}$ and $\mathrm{Cu}$ under elevated metal conditions. In particular, DA3E had an unusually high Ni content in the treated shoot relative to the control shoot while DA5E showed a similar behavior for $\mathrm{Cu}$. These results suggest that the mechanism(s) for $\mathrm{Ni}$ and $\mathrm{Cu}$ translocation to shoots under elevated metal conditions may be altered by the addition of chromosomes $3 \mathrm{E}$ and $5 \mathrm{E}$, respectively.

It is also interesting to note that relative to control conditions, little accumulation or even suppression of shoot content in $\mathrm{Mn}, \mathrm{Fe}$, and $\mathrm{Cu}$ was observed for most genotypes under elevated metal conditions (Figure 1B). The lack of excess $\mathrm{Mn}$ accumulation in shoots presumably reflected the lack of excess uptake into roots (Figure 1A). However, this was not the case for $\mathrm{Fe}$ and $\mathrm{Cu}$ since a substantial accumulation of the two metal ions did occur in roots. It is possible that the $\mathrm{Fe}$ and $\mathrm{Cu}$ translocation to shoot was either disturbed by the treatment or highly regulated in wheat. Although a significant accumulation of $\mathrm{Zn}, \mathrm{Ni}$, and $\mathrm{Cd}$ was observed in 
shoots of all genotypes, the extent of the accumulation was much less than that in roots. This may be again related to the perturbation in translocation capacity and/or feedback control.

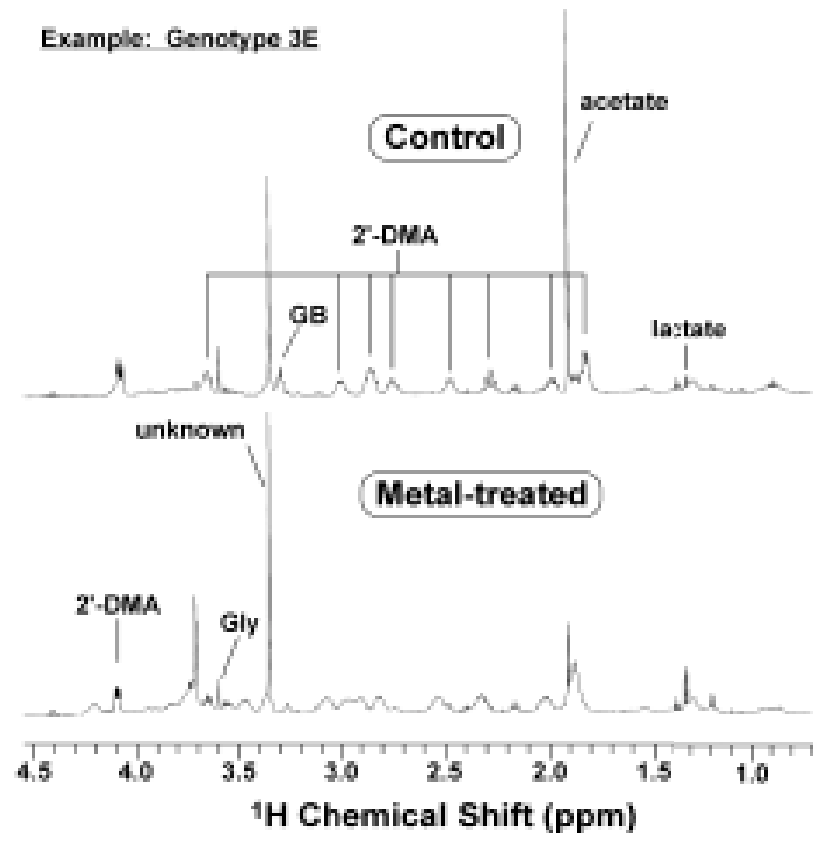

Figure 2. ${ }^{1} H$ NMR profiles of example wheat root exudates from control and metal treatments. The ${ }^{1} H$ NMR spectra were acquired from control and metal-treated DA3E as described in Materials and Methods. Besides the major components that are labeled, a number of less abundant components were confirmed from $G C$ $M S$ analysis (data not shown) including alanine, valine, leucine, isoleucine, succinate, proline, fumarate, serine, threonine, phenylalanine, glutamate, and citrate.

Exudates production and their profiles. Under control conditions, the parent CS produced the highest amount of root exudates per $g$ root mass while DA2E, DA3E, and AgCS were among the lowest in exudation. This suggests that root exudation was perturbed by the addition of L. elongatum chromsomes $2 \mathrm{E}$ and $3 \mathrm{E}$. In contrast, under metal treatment conditions, DA2E, DA3E, and AgCS produced higher amounts (50-70\%) of exudates per $g$ root mass than the parent CS. DA2E and AgCS also had the highest biomass reduction due to the metal treatment, which could be related to a 
resource diversion to root exudation, in addition to the toxic effect of metal accumulation (Figure 1A).

Analysis of the crude exudates by ${ }^{1} \mathrm{H}$ NMR revealed the abundance of components including the phytosiderophore 2'-deoxymugineic acid (2'DMA), lactate, acetate, glycinebetaine (GB), glycine (Gly), and an unknown compound (Figure 2). Identification of these components by 2D ${ }^{1} \mathrm{H}$ total correlation spectroscopy (TOCSY), ${ }^{1} \mathrm{H}-{ }^{13} \mathrm{C}$ heteronuclear single quantum coherence spectroscopy (HSQC), and heteronuclear multiple bond correlation spectroscopy (HMBC) ${ }^{5}$ will be presented elsewhere.

The concentrations of exudate components, 2'-DMA (Figure 3), acetate, and the unknown (data not shown), followed the same pattern across all lines as the root concentration of $\mathrm{Mn}, \mathrm{Fe}, \mathrm{Cu}$, and $\mathrm{Zn}$ under control conditions. DA2E, 3E and AgCS ranked among the highest for both exudate concentrations and metal content. This is in contrast to their low total exudation by dry weight (see above), which illustrates the necessity for determining specific exudate profile, not just total exudation, for a functional understanding of metal ion mobilization and sequestration. Since 2'-DMA is known to be involved in Fe and $\mathrm{Zn}$ uptake into wheat roots ${ }^{19}$, such genotypic correlation suggests that the gene(s) involved in 2'-DMA production and thus $\mathrm{Fe}$ and $\mathrm{Zn}$ uptake may be located on $L$. elongatum chromosomes $2 \mathrm{E}$ and $3 \mathrm{E}$. This is consistent with the earlier conclusion based on root metal content (see above). Whether the same case holds for acetate and the unknown awaits further investigation. In addition, PS has been shown to mobilize $\mathrm{Mn}$ and $\mathrm{Cu}$ from soil and the 
MnPS and CuPS complexes are taken up by graminaceous roots albeit less preferentially than the uptake of FePS ${ }^{20}$. Thus, the covariation of Mn and

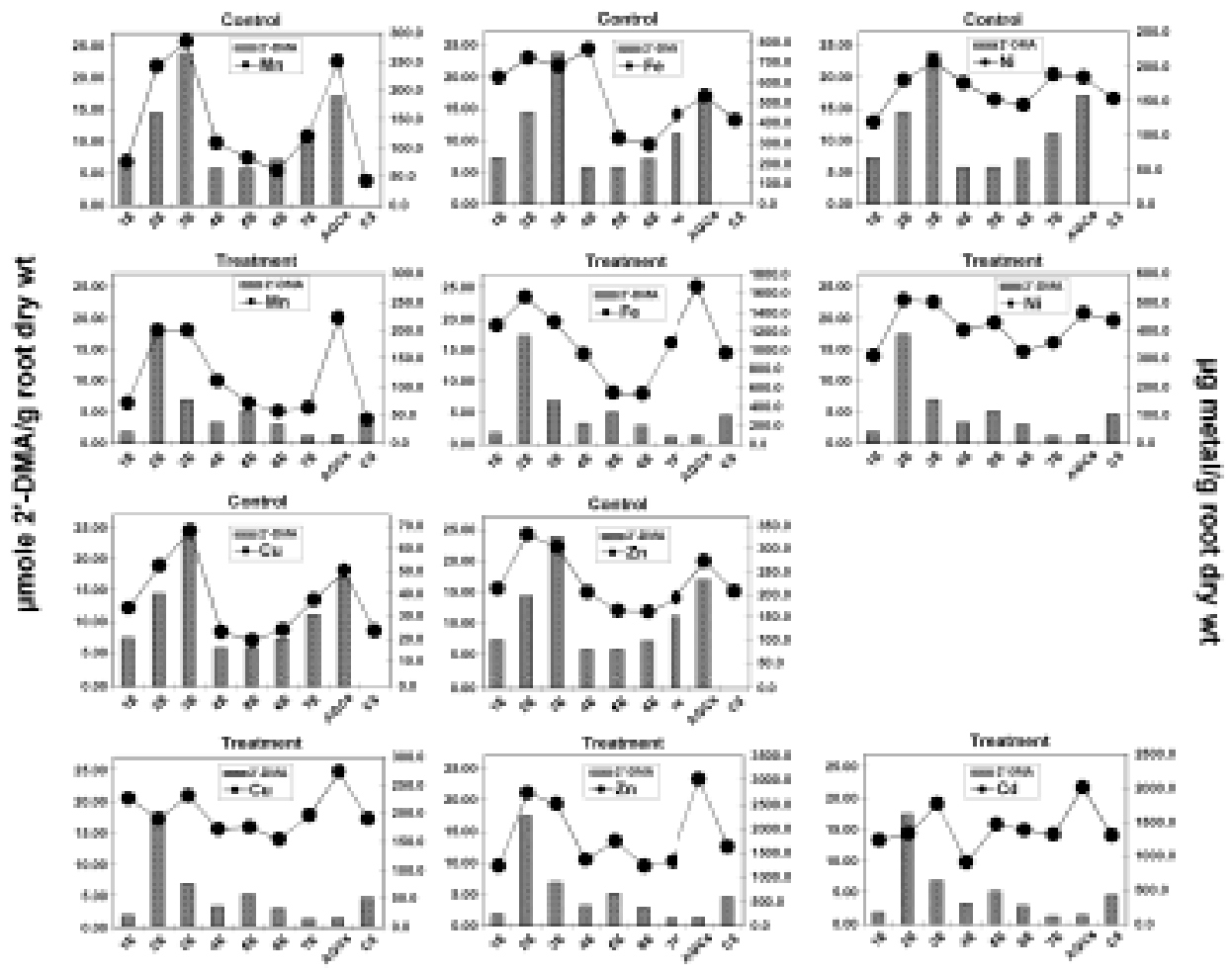

Figure 3. Genotypic variations in 2'-DMA exudate (gray bars, left ordinate) and $\mathrm{Mn}, \mathrm{Fe}$, $\mathrm{Ni}, \mathrm{Cu}, \mathrm{Zn}$, and $\mathrm{Cd}$ content (black circles, right ordinate) of control and metal-treated wheat roots. Exudate components and metals were quantified according to the procedures described in Materials and Methods. The abscissa for each graph are the nine genotypes $1 E, 2 E, 3 E, 4 E, 5 E, 6 E, 7 E, A g C S$, and $C S$.

$\mathrm{Cu}$ with 2'-DMA concentrations was to be expected. However, the relationship for $\mathrm{Ni}$ and the three exudate components was ambiguous (e.g. Figure 3), which suggests that $\mathrm{Ni}$ may be absorbed by a mechanism different from that via these components. It should also be noted that the 
amplitude of genotypic responses in root metal content (Figures 1A and 3) may be attenuated to some extent, due to the accessibility of exudate components (therefore their metal ion complexes) by each set of three genotypes (DA1E-3E, DA4E-6E, and DA7E/AgCs/CS) grouped in the same container.

Compared to control conditions, the genotypic covariation for 2'DMA, $\mathrm{Mn}, \mathrm{Fe}, \mathrm{Zn}$, and $\mathrm{Cu}$ became much less discernable under metal treatment (Figure 3). This was also the case for $\mathrm{Cd}$. It is possible that the excess free metal ions under the elevated metal treatment is readily available to plant roots, which in turn requires less assistance from exudation of MIL such as 2'-DMA. Consequently, metal uptake into roots becomes decorrelated with the level of exudation for these components. This account is also consistent with an overall reduction in the exudation of 2'-DMA, acetate, and the unknown induced by the metal treatment.

Intracellular MIL: SH-rich peptides and proteins. It is wellrecognized that thiol-rich peptides such as metallothioneins (MT) and phytochelatins (PC, also known as class III metallothioneins) are induced for intracellular metal sequestration, particularly for $\mathrm{Cd}$ 21-23. Through complexation with metal ions, these peptides help improve biological tolerance to metal accumulation. However, the analysis of these peptides has been relatively labor-intensive and limited in scope.

Here, we present a preliminary method that combined bromobimane (BrB) fluorescent tagging with polyacrylamide gel electrophoresis to greatly simplify the analysis of all thiol-containing proteins and peptides. Figure 4 illustrates the fluorescence gel patterns of BrB-derivatized root 
and shoot extracts of different wheat genotypes, along with those of the rabbit MT and Cd-exposed yeast extract. At least three bands in the $<3.5$ $\mathrm{kD}$ region were observed in the yeast extract which may correspond to $\mathrm{PC}_{2}, \mathrm{PC}_{3}$, and $\mathrm{PC}_{4}$, known to be produced under $\mathrm{Cd}$ treatment 22 .

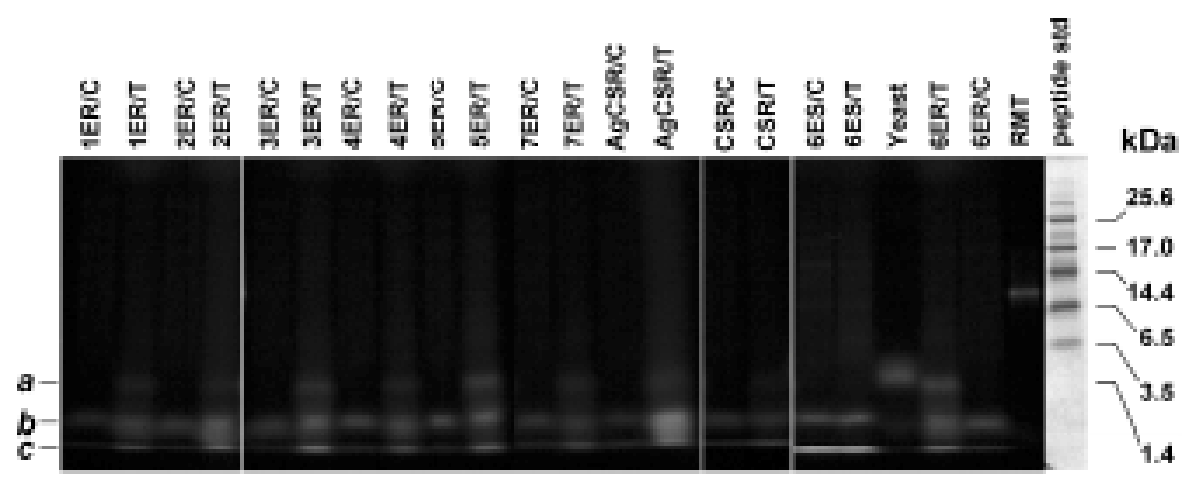

Figure 4. SDS-PAGE pattern of thiol-rich pepetide extracts of wheat genotypes. The thiolrich peptides from 9 wheat genotypes were extracted, derivatized, separated by electrophoresis, and imaged as described in Materials and Methods. R/C, R/T, S/C, and $S / T$ denote root/control, root/metal treated, shoot/control, and shoot/metal treated, respectively. Rabbit metallothionein (RMT) and Cd-treated yeast (Saccharomyces pombe, obtained from Dr. D. Ow) were also derivatized and electrophoresed along with the wheat extracts and peptide standards (BioRad). The peptide standards were stained with Coomassie blue $G-250$. The dominant yeast band of $>1.4 \mathrm{kDa}$ was presumably $P_{4}$ (phytochelatin with chain length $=4$ ) or PC with higher chain lengths 16. The bands from wheat are labeled as $a, b$, and $c$.

The gel patterns of wheat roots were distinctly different between control and metal treatments, with an additional band of approximately 1.4 $\mathrm{kD}(a)$ appeared in all metal treated but not in control roots. This band had an apparent molecular weight similar to the calculated weight of BrBderivatized $\mathrm{PC}_{3}$. The two bands below the $1.4 \mathrm{kD}$ band $(b, c)$ also shows different intensity between control and treated roots. Moreover, there 
were genotypic differences in the band pattern, and in particular band $b$ of metal-treated $\mathrm{AgCS}$ root $(\mathrm{AgCSR} / \mathrm{T})$ had an unusually high intensity. It appeared that these peptides were induced by the metal treatment and that they are likely to be phytochelatins. We are currently conducting further analysis of these peptides to confirm their identity. It is also interesting to note that wheat shoots (e.g. $6 \mathrm{ES} / \mathrm{C}$ and $6 \mathrm{ES} / \mathrm{T}$ ) was very low in band $a$ and that no significant difference in bands $b$ and $c$ was observed between control and metal treatments. This is correlated with the much lower level of metal ( $\mathrm{Fe}, \mathrm{Ni}, \mathrm{Cu}, \mathrm{Zn}$, and $\mathrm{Cd}$ ) accumulation in metal-treated shoots than roots. These results suggest that band $a$ may be important in sequestering excess metal ions to reduce their toxicity in wheat roots. Moreover, the thiol-rich peptide pattern of wheat differed somewhat from that of yeast, where the yeast peptide pattern was more enriched in a higher molecular weight component than that of wheat. This could reflect a difference in the biosynthesis of these peptides.

Other MIL profiles in wheat roots. In addition to the thiol-rich peptides, the root tissues were analyzed broadly for MIL by GC-MS and ${ }^{1} \mathrm{H}$ NMR. Figure 5 shows the genotypic profile of some of the MIL obtained from the GC-MS analysis along with the root Fe profile. The identity of these compounds was also confirmed by the ${ }^{1} \mathrm{H}$ NMR analysis (data not shown).

Under control conditions, no discernable relationship was observed between these MIL and Fe content across all lines. However, under elevated metal conditions, a genotypic covariation between $\mathrm{Fe}$, citrate, and malate was evident while an overall negative correlation was noted 
between Fe and lysine for DA1E through DA6E (Figure 5). A similar trend also applied to $\mathrm{Zn}$ and $\mathrm{Mn}$ (cf. Figures 1A and 3). Moreover, the

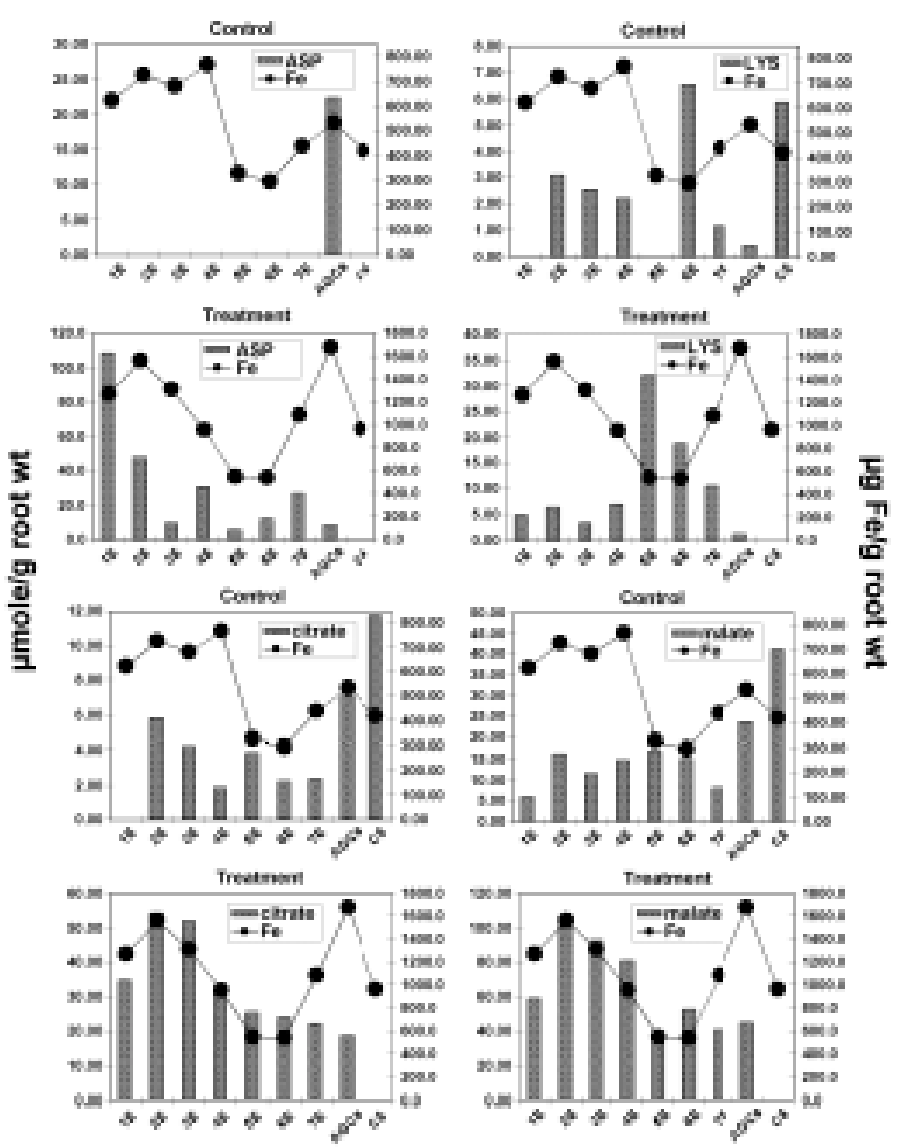

Figure 5. Genotypic variations in other metal ion ligands and Fe content of control and metaltreated wheat roots. Metal ion ligands (MIL) and other root metabolites were analyzed as described in Materials and Methods. Gray bar and filled circle denote MIL and Fe contents, respectively. The abscissa for each graph are the nine genotypes $1 E, 2 E$, $3 E, 4 E, 5 E, 6 E, 7 E$, $A g C S$, and $C S$.

concentrations of these MIL increased many fold in response to the metal buildup in roots, except for that of asparagine in AgCS (the data for CS was missing due to lack of tissue for analysis). Among all lines, DA2E and DA3E demonstrated the highest accumulation of malate and citrate. Therefore, these MIL and the SH-rich peptides above may collectively 
participate in the binding of excess metal ions, presumably to reduce their toxicity to roots. The genetic component(s) involved in this response may be located on chromosomes $2 \mathrm{E}$ and $3 \mathrm{E}$.

In conclusion, a comprehensive screening for element and metabolites by XRF, ${ }^{1} \mathrm{H}$ NMR, GC-MS, and SDS-PAGE revealed significant differences in metal ion accumulation, root exudation of MIL, and buildup of endogenous MIL in roots among different genetic stocks of wheat. This approach provided clues to the biochemistry and genetic components involved in metal mobilization and sequestration as well as metabolic adaptation to metal toxicity in plants. Such fundamental knowledge should facilitate the design and efficacy of plant-based remediation of metal contamination.

\section{Acknowledgement}

This work was supported by the DOE/EMSP grant \#DE-FG0796ER20255) and EPA grant \#R825960010. We are grateful to Dr. J. Dvorak for his comments on the manuscript, Dr. D. Ow for supplying the yeast culture, R. Kaufman for assistance in thiol-rich peptide analysis, and T.A. James for assistance on ED-XRF method development. We also wish to acknowledge Dr. Nancy Isern for her assistance with the NMR measurements and Environmental Molecular Science Laboratory (Richland, WA) for the NMR access. 


\section{References}

1. Marschner, H. in Plant roots : the hidden half; Waisel, Y.; Eshel, A.; Kafkafi, U., Eds; M. Dekker: New York, 1991, pp 503-526.

2. Kawai, S.; Takagi, S.; Sato, Y. J. Plant Nutr. 1988, 11, 633-642.

3. Romheld, V. Plant and Soil 1991, 130, 127-134.

4. Hopkins, B. G.; Whitney, D. A.; Lamond, R. E.; Jolley, V. D. J. Plant Nutr. 1998, 21, 2623-2637.

5. Fan, T. W. M.; Lane, A. N.; Pedler, J.; Crowley, D.; Higashi, R. M. Analyt. Biochem. 1997, 251, 57-68.

6. Takagi, W.-I. In Iron chelation in plants and soil microorganisms; Barton, L.; Hemming, B. C., Eds; Academic Press: San Diego, 1993, pp 111-131.

7. Nomoto, K.; Yoshioka, H.; Arima, M.; Fushiya, S.; Takagi, S.; Takemoto, T. Chimica 1981, 35, 249-250.

8. Rommel, R.; Jenkins, B. C. Wheat Inf. Serv., 1959, 9-10, 23.

9. Dvorak, J. Canad. J. Genet. Cytol. 1980, 22, 237-259.

10. Dvorak, J.; Chen, K. C. Canad. J. Genet. Cytol. 1984, 26, 128-132.

11. Tuleen, N. A.; Hart, G. E. Genome 1988, 30, 519-524.

12. Epstein, E., Mineral Nutrition of Plants: Principles and Perspectives; John Wiley and Sons: New York, 1972.

13. Fahey, R.C.; Newton, G.L. Methods in Enzymology 1987, 143, 85-96.

14. Schagger, H.; von Jagow, G. Analyt. Biochem. 1987, 166, 368-379.

15. Fan, T. W. M.; Higashi, R. M.; Frenkiel, T. A.; Lane, A. N. J. Exp. Bot. 1997, 48, 1655-1666.

16. Fan, T. W.-M.; Lane, A. N.; Martens, D.; Higashi, R. M. Analyst 1998, 123, 875-884.

17. Fan, T. W.-M. Progr. Nucl. Magn. Reson. Spectrosc. 1996, 28, 161-219.

18. Fan, T. W. M.; Colmer, T. D.; Lane, A. N.; Higashi, R. M. Analyt. Biochem. 1993, 214, 260-271.

19. Zhang, F. S.; Romheld, V.; Marschner, H. Soil Sci. Plant Nutr. 1991, 37, 671-678.

20. Römheld, R. Plant and Soil 1991, 130, 127-134.

21. Kaigi, J., Schaffer, A Biochemistry 1988, 27, 8509-8515.

22. Grill, E.; Winnacker, E.-L.; Zenk, M. H. Science 1985, 230, 674-676.

23. Rauser, W.E. Annu. Rev. Biochem. 1990, 59, 61-86. 